\title{
Fatigue Strength Improvement Due to Alloying Steel Weld Toes With WC-Tool Constituent Elements Through Friction Stir Processing
}

Hajime Yamamoto ( $\nabla$ h.yamamoto@jwri.osaka-u.ac.jp )

Osaka University https://orcid.org/0000-0001-6562-5624

\section{Shodai Koga}

Osaka University

\section{Kazuhiro Ito}

Osaka University

Yoshiki Mikami

Osaka University

\section{Research Article}

Keywords: Friction stir processing, Tool wear, Alloying, Fatigue strength, Post-weld treatment, High-strength low-alloy steel

Posted Date: October 13th, 2021

DOI: https://doi.org/10.21203/rs.3.rs-962570/v1

License: @ (i) This work is licensed under a Creative Commons Attribution 4.0 International License. Read Full License

Version of Record: A version of this preprint was published at The International Journal of Advanced Manufacturing Technology on January 19th, 2022. See the published version at https://doi.org/10.1007/s00170-022-08690-7. 


\section{Abstract}

Friction stir processing (FSP) enables surface modifications using a rotational tool and can likely be applied as a new post-weld treatment for improving fatigue strength. When applying FSP to high strength materials, tool wear occurring at the interface between the tool tip and the topmost steel layer has been regarded as an unavoidable issue and is related to the tool rotational speed. The present study investigated the relationship between the tool rotational speed and fatigue strength of arc-welded high-strength low-alloy (HSLA) steel joints with weld toes subjected to FSP using a spherical-tip WC tool. FSP was conducted on the weld toe of HSLA steel joints with various tool rotational speeds. Tool wear increased with increase in tool rotational speed, and consequently contents of constituent elements of the WC tool increased in the topmost steel layer of weld toes, leading to large increase of fatigue strength. One reason for the increase with tool rotational speed is significant increase of solid solution hardening due to supersaturated $\mathrm{W}$ and $\mathrm{C}$ in the topmost steel layer consisting of martensite laths. The hardened topmost steel layer prevented fatigue crack initiation, and the increased fatigue strength depended on the contents of supersaturated W and C.

\section{Introduction}

Fatigue strength of arc-welded joints is commonly said to be lower than that of the base metal, because of stress concentration, tensile residual stress, and deterioration of the mechanical properties due to microstructural change at the weld toe. Various post-weld treatments have been proposed to increase fatigue strength of the welds, and are generally divided into two groups of residual stress modification, those of peening [1-4] and post-weld heat treatment $[5,6]$, and weld geometry modification such as grinding [7-9] and remelting [10-12]. Residual stress modification is more effective than weld geometry modification under low applied stress amplitude, but seems not effective under high applied stress amplitude, because of residual stress relaxation during fatigue [13]. On the other hand, fatigue strength and life increased by reducing stress concentration at the weld toe, and independently of the applied stress amplitude. In addition, remelting the weld toe using arc plasma or laser as a heat source led not only to smoothing of the weld surface profile, but also removal of internal defects, including cracks, without reducing plate thickness [11]. However. it has been reported that remelting by means such as tungsten inert gas dressing caused softening around the remelted zone, which disturbed large improvement of fatigue strength of the high-strength steel welds [12].

On the other hand, we reported that friction stir processing (FSP) significantly increased the fatigue strength of arc-welded steel joints [14-18] and can likely be used as a new post-weld treatment. FSP is a surface modification technique using a rotational tool, based on the principle of friction stir welding (FSW) [19]. The stir zone (SZ) produced locally by FSP can consist of fine homogeneous microstructure, resulting in mechanical properties superior to those of the base metal [20-23]. In addition, material flow during FSP contributes to elimination of internal defects and refinement of coarse precipitates, which can become crack initiation sites, resulting in the improvement of fatigue properties of cast alloys [24-26]. Considering these advantages, Costa et al. also reported that FSP on the weld toes increased fatigue strength of several aluminum alloy joints fabricated by metal inert gas welding [27-30].

Among the papers mentioned above, we demonstrated the fatigue strength improvement of arc-welded highstrength low-alloy (HSLA) steel joints with weld toes that had been subjected to FSP using a spherical-tip WC 
tool [17]. That was the first paper regarding alloying the topmost steel layer of the weld toes with $\mathrm{W}$ and $\mathrm{C}$, which are constituent elements of the WC tool, accompanied with the tool wear during FSP. The supersaturated $\mathrm{W}$ and $\mathrm{C}$ caused significant solid solution hardening in the topmost steel layer of the weld toes and contributed to the improvement of the fatigue strength. Importantly, the results indicated positive utilization of the tool wear during FSP as a new line of thought, as the tool wear has been considered as an unavoidable issue in FSW/FSP of high strength materials.

However, the relationship between the fatigue strength increase and tool rotational speed related to contents of the supersaturated $W$ and $C$ was not systematically shown in the previous study [17], which focused only on the applicability of FSP to the steel weld toe. We therefore intended to clarify influence of the tool rotational speed on improving fatigue strength. Increase of the tool rotational speed would increase the WC tool wear, occurring at the interface between the tool tip and a topmost steel layer, leading to increasing contents of constituent elements of the WC tool in the topmost steel layer of weld toes. This would increase solid solution hardening and consequently increase fatigue strength. In the present study, the relationship between the tool rotational speed and fatigue strength of arc-welded HSLA steel joints with weld toes subjected to FSP using a spherical-tip WC tool was investigated.

\section{Experimental Procedures}

HSLA steel plates of 10-mm-thickness and filler metals were prepared, with the chemical compositions as shown in Table 1. Three-pass $\mathrm{CO}_{2}$ gas-shielded arc welding was conducted in V-groove with a root gap of 5 $\mathrm{mm}$ and angle of $60^{\circ}$ in accordance with the conditions shown in Table 2. FSP was conducted on weld toes of the obtained butt-welded HSLA steel joints using a spherical-tip WC tool. The tool, having a 15-mm-diameter spherical tip with a curvature radius of $10 \mathrm{~mm}$ as shown in Fig. 1(a), was made of WC particles (88-91 mass $\%$ ) with a size range of about 2-4 $\mu \mathrm{m}$ and Ni-based binder. FSP was conducted at positions $2 \mathrm{~mm}$ away from the right and left ends of the weld toe for the prevention of flash formation [17]. The positions corresponded to the tool rotational axis (Fig. 1(b)). The tool was tilted backward $3^{\circ}$ and operated at a travel speed of $100 \mathrm{~mm} / \mathrm{min}$ along the weld bead and downward force of $18.3 \mathrm{kN}$ with various rotational speeds of 400-1000 rpm (Fig. 1(c)). The advancing side (AS) and retreating side (RS) during FSP corresponded to the excess weld metal and base metal positions, respectively.

Table 1 Chemical compositions of the base and filler metals (mass\%)

\begin{tabular}{|lllllllllllll|}
\hline Material & $\mathrm{C}$ & $\mathrm{Si}$ & $\mathrm{Mn}$ & $\mathrm{P}$ & $\mathrm{S}$ & $\mathrm{Cu}$ & $\mathrm{Ni}$ & $\mathrm{Cr}$ & $\mathrm{Mo}$ & $\mathrm{V}$ & $\mathrm{Al}$ & $\mathrm{Fe}$ \\
\hline $\begin{array}{l}\text { Base } \\
\text { metal }\end{array}$ & 0.14 & 0.23 & 1.08 & 0.014 & 0.006 & 0.01 & 0.01 & 0.02 & - & 0.002 & 0.028 & Bal. \\
$\begin{array}{l}\text { (HSLA } \\
\text { steel) }\end{array}$ & & & & & & & & & & & & \\
$\begin{array}{l}\text { Filler } \\
\text { metal }\end{array}$ & 0.03 & 0.55 & 1.55 & 0.011 & 0.007 & 0.02 & 0.01 & 0.02 & $<$ & $<$ & - & Bal. \\
\hline
\end{tabular}

Table $2 \mathrm{CO}_{2}$ gas-shielded arc welding parameters 


\begin{tabular}{|ccccc|}
\hline Pass & $\begin{array}{c}\text { Welding current, } \\
(\mathrm{A})\end{array}$ & $\begin{array}{c}\text { Arc voltage, } \\
(\mathrm{V})\end{array}$ & $\begin{array}{c}\text { Welding speed, } \\
(\mathrm{mm} / \mathrm{min})\end{array}$ & $\begin{array}{l}\text { Torch drag angle, } \\
\left({ }^{\circ}\right)\end{array}$ \\
\hline 1st & 170 & 22 & 130 & - \\
\hline 2nd & 280 & 32 & 200 & - \\
\hline 3rd & 280 & 29 & 300 & 5 \\
\hline
\end{tabular}

Cross-sectional images of the weld toes with and without FSP were taken using an optical microscope (OM) and a scanning electron microscope (SEM). Specimens with mirror-polished surfaces for cross-sectional images were etched with 2 vol\% nital solution. Major elements in both the steel and the tool were analyzed using an electron probe microanalyzer (EPMA). To obtain a high-magnification image of a nanoscale area in the weld toe after FSP, thin film specimens were taken from the specimens to obtain cross-sectional images using a focused ion beam machining device. Microstructure observation and elemental analysis of the obtained thin film specimens were conducted using a transmission electron microscope (TEM) equipped with an energy dispersive X-ray spectroscope (EDS). Vickers hardness tests were carried out at room temperature with an applied load of $49 \mathrm{mN}$ and loading time of $15 \mathrm{~s}$.

Four-point bending fatigue tests were carried out at room temperature with a sinusoidal waveform of $20 \mathrm{~Hz}$ as a function of maximum applied stress with a stress ratio of 0.1 . Specimens with welds at the center $(145 \mathrm{~mm}$ long $\times 10 \mathrm{~mm}$ wide $\times 10 \mathrm{~mm}$ thick) were prepared by cutting the butt-welded steel plates with and without FSP using an electrical discharge machine. Outer and inner spans of 10-mm-diameter pins were 90 and $50 \mathrm{~mm}$, respectively. The weld bead was located at the center of the inner span, and the base metals on both right and left sides of the weld bead were included between inner-span pins. To characterize the fracture location and crack initiation site, the cross section and fracture surface of the specimen after the fatigue test were observed by OM and SEM. To characterize the local fatigue strength of the topmost steel layer at the weld toe modified by FSP, small flat tensile specimens with a dumbbell shape (gauge length of $1 \mathrm{~mm}$, gauge width of $0.5 \mathrm{~mm}, 5$ $\mathrm{mm}$ square gripped ends, and thickness of $0.5 \mathrm{~mm}$ ) were taken from the topmost layer of the weld toe with and without FSP, and tensile tests were conducted at room temperature at a strain rate of $1.0 \times 10^{-3} \mathrm{~s}^{-1}$.

\section{Results And Discussion}

\subsection{Microstructural characterization of weld toes}

Fig. 2 shows cross-sectional OM images of the as-welded joint. Typical weld toe radius and angle were measured to be about $0.27 \mathrm{~mm}$ and $27^{\circ}$, respectively (Fig. 1(b)). The base metal and weld toe consisted of ferrite-pearlite layered structure (Figs. 2(c), 2(d)) and coarse bainitic ferrite grains (Figs. 2(e), 2(f)).

FSP was conducted on the weld toe surfaces to improve fatigue strength of the butt-welded joints. Fig. 3 shows cross-sectional OM and SEM images of the weld toes with FSP at the tool rotational speeds of 400, 600,800 , and 1000 rpm (hereafter, samples FSP400, FSP600, FSP800, and FSP1000, respectively). FSP changed weld toe geometry due to plastic deformation, in addition to formation of the SZ. The weld toe radius was significantly increased to about $3.69,2.65,3.53$, and $3.79 \mathrm{~mm}$ in samples FSP400, FSP600, FSP800, and 
FSP1000, respectively, but with slightly higher weld toe angles (Figs. 3(a)-(d)) in comparison to that of the aswelded toe (Fig. 2(b)). These macroscopic changes did not seem to depend on tool rotational speed. On the other hand, a surface morphological and microstructural feature of the topmost layer of the weld toes after FSP varied with tool rotational speed: a notched surface was observed in FSP400 (Fig. 3(e)), while smooth surfaces were observed in FSP600, FSP800, and FSP1000 (Figs. 3(f)-3(h)). The notched surface in FSP400 can be attributed to materials having been removed at the front of the tool and subsequently accumulating behind the tool. The FSP condition of $400 \mathrm{rpm}$ was not appropriate for sound surface modification on the weld toe. In microstructure of the topmost layer including the SZ, there was an obvious difference in addition to significant grain refinement in all weld toes with FSP. In the OM images for FSP800 and FSP1000 (Figs. $3(\mathrm{~g}), 3(\mathrm{~h})$ ), discontinuous and continuous areas with white contrast were observed at the outermost surface layer, in comparison to those for FSP400 and FSP600 (Figs. 3(e), 3(f)). The white contrast areas correspond to the portions alloyed with constituent elements of the WC tool, and the thicker portion for FSP1000 was provided by the faster tool rotational speed. This suggests that the tool wear amount increased with increasing tool rotational speed. To characterize microstructure of the topmost layer at the weld toe, the specimen surface was etched with 2 vol\% nital solution, and cross-sectional SEM images of the outermost surface layer and a layer around $100 \mu \mathrm{m}$ below the surface were obtained, as shown in Figs. 3(i)-3(I) and $3(m)-3(p)$, respectively. Fine equiaxed polygonal ferrite grains were observed in both layers mainly in FSP400 and FSP600 (Figs. 3(i), 3(j), 3(m), 3(n)). The volume fraction of bainitic ferrite grains increased with increasing tool rotational speed in the layer $100 \mu \mathrm{m}$ below the surface, suggesting that the peak temperature during FSP was beyond the phase transformation temperature and the volume fraction of transformed austenite grains increased. The layer eventually showed a fully bainitic structure in FSP1000 (Fig. 3(p)). This indicates that the peak temperature during FSP exceeded the $A_{C 3}$ point with the fully austenite transformation. The bainitic ferrite grains arose through transformation from the austenite phase during cooling in FSP, while polygonal ferrite grains arose through dynamic recrystallization during FSP. The outermost surface layer having smooth continuity formed in FSP800 and FSP1000 is considered to contain tool constituent elements of W and C, as explained in a previous study [31], as shown in Figs. 3(k) and 3(i). This suggests that the layer consisted of fully martensite structure with ultrafine laths.

To identify the elemental contents and their influence on the hardness in the outermost surface layer, EPMA and Vickers hardness tests were conducted. Fig. 4 shows relationship between increment in $\mathrm{W}$ and $\mathrm{C}$ contents and hardness with respect to depth from the weld toe surface. The increment was estimated by subtracting the average content obtained in the topmost layer of the as-welded toe from the content measured using EPMA. Increment in the $\mathrm{W}$ and $\mathrm{C}$ contents was concentrated beneath the surface and the segregated depth was about $50 \mu \mathrm{m}$ in $\mathrm{W}$ and $100 \mu \mathrm{m}$ in C (Figs. 4(a), 4(b)). The increment of W and C contents increased with increasing tool rotational speed and was estimated to be about 2.36 and 2.17 at\%, respectively, in sample FSP1000. The hardness increment in the outermost surface layer with respect to the base metal exhibited similar trend of increment in W content in each specimen (Fig. 4(c)). The increment was small in FSP400 and FSP600, and increased with increasing tool rotational speed in FSP800 and FSP1000. Note that the hardness increment due to $\mathrm{W}$ and $\mathrm{C}$ solid solution hardening was larger than that due to grain refinement (see FSP400 and FSP600). The average hardness of the outermost surface layer was 552 and 878 HV, respectively, in FSP800 and FSP1000, and was higher than that of the water-quenched base metal (449 HV) consisting of fully martensite structure. 
To further characterize the distribution of tool constituent elements in the outermost surface layer, TEM-EDS analyses were conducted for the thin film specimens taken from the weld toe surfaces (Figs. 3(j)-3(I)). Fig. 5 shows TEM-EDS results obtained in samples FSP600, FSP800, and FSP1000. Polygonal ferrite grains about a few $\mu \mathrm{m}$ in average diameter were observed in the outermost surface layer of the weld toe in FSP600, as shown in the TEM-bright field (BF) images (Figs. 5(a), 5(b)). W segregation was hardly observed in any ferrite grains or at their boundaries in the EDS-W map image (Fig. 5(c)). On the other hand, grain structure in the outermost surface layer of the weld toes in FSP800 and FSP1000 (Fig. 5(d), 5(g)) became finer than that in FSP600 (Fig. 5(a)). Enlarged images showed obvious change in grain morphology, and the layer included fine elongated grains (Fig. 5(e), 5(h)). The EDS-W map images (Figs. 5(f), 5(i)) exhibited higher homogeneously distributed W content than that in FSP600 (Fig. 5(c)). In addition, a few W-rich particles were observed in FSP1000 (Fig. 5(i)).

To identify W content in the outermost layer, EDS quantitative analyses were conducted at points A-I in the steel matrix in Figs. 5(b), 5(e), and 5(h) and at points 1-3 in the W-rich particles in Fig. 5(g), indicated by red and yellow arrows, respectively. A summary is presented in Table 3 . The average $\mathrm{W}$ contents obtained in the steel matrix of samples FSP600, FSP800, and FSP1000 based on the TEM-EDS analyses were estimated to be $0.11,1.43$, and 2.25 at\%, in good agreement with those obtained using a $5 \mu$ m-diameter electron-beam spot using EPMA (Fig. 4(a)), suggesting that the tool constituent W atoms were homogeneously distributed in the topmost steel matrix layer after FSP. On the other hand, the W-rich particles observed in FSP1000 exhibited average $\mathrm{W}$ content of 23.42 at\%, suggesting that the particle could be an embedded $\mathrm{Fe}_{4} \mathrm{~W}_{2} \mathrm{C}$ fragment that had dropped out of the WC tool tip and was milled at the interface between the tool and steel surface. $\mathrm{Fe}_{4} \mathrm{~W}_{2} \mathrm{C}$ particles were reported to form at the tool tip as result of reaction of a WC particle with Fe atoms diffused from the steel matrix [31], together with decomposition of most of the fragment into $\mathrm{W}$ and $\mathrm{C}$ atoms during milling at the interface under high temperature and pressure due to FSP friction. Most of the tool constituent elements seem to have dissolved in the outermost surface layer of steel matrix austenitized around the peak temperatures during FSP, followed by martensitic transformation during cooling, resulting in fine martensite laths in the outermost surface layer (Fig. 5(e), 5(h)). Note that the solid-soluble W and C contents in the a-Fe phase were almost zero at room temperature. The hardness of the topmost layer was significantly higher than that of the water-quenched base metal. This can be explained by solid solution hardening due to the supersaturated $\mathrm{W}$ and $\mathrm{C}$ atoms (WC-tool constituent elements). The hardening is associated with large lattice distortion caused by substitutional solid solution of the extra W into the martensite as well as interstitial solid solution of the extra $\mathrm{C}$. The higher solid solute $\mathrm{W}$ contents could contribute to the higher increase in hardness in FSP1000. The W-rich particles cannot have effectively increased the hardness, since their size of about 100 $\mathrm{nm}$ was too large to impede the movement of dislocations.

Table $3 \mathrm{~W}$ contents obtained at points A-I and 1-3 in Fig. 5 indicated by red and yellow arrows in the steel matrixes and particles, respectively, based on EDS quantitative analyses 


\begin{tabular}{|c|c|c|c|c|}
\hline Code & \multicolumn{2}{|c|}{ Measuring point } & W content, (at $\%)$ & Average \\
\hline \multirow[t]{3}{*}{ FSP600 } & \multirow[t]{3}{*}{ Matrix } & $A$ & 0.12 & \multirow[t]{3}{*}{0.11} \\
\hline & & $\mathrm{B}$ & 0.12 & \\
\hline & & $\mathrm{C}$ & 0.10 & \\
\hline \multirow[t]{3}{*}{ FSP800 } & \multirow[t]{3}{*}{ Matrix } & $\mathrm{D}$ & 1.40 & \multirow[t]{3}{*}{1.43} \\
\hline & & $E$ & 1.44 & \\
\hline & & $\mathrm{F}$ & 1.44 & \\
\hline \multirow[t]{6}{*}{ FSP1000 } & \multirow[t]{3}{*}{ Matrix } & G & 2.36 & \multirow[t]{3}{*}{2.25} \\
\hline & & $\mathrm{H}$ & 2.27 & \\
\hline & & I & 2.13 & \\
\hline & \multirow[t]{3}{*}{ Particle } & 1 & 18.46 & \multirow[t]{3}{*}{23.42} \\
\hline & & 2 & 27.38 & \\
\hline & & 3 & 24.42 & \\
\hline
\end{tabular}

\subsection{Fatigue strength of welded joints with FSP depending on tool rotational speed}

Fatigue strength of weld toes with the FSP-modified topmost layer was investigated. The FSP-modified topmost layer was alloyed with WC-tool constituent elements together with grain refinement. Their applied nominal stress amplitude dependence on number of cycles to failure (S-N diagram) is shown in Fig. 6, together with those of an as-welded joint and a base metal. Since the specimens did not fail up to $2 \times 10^{6}$ cycles (shown with additional arrows on symbols), this number was defined as the fatigue limit. The other joint specimens failed due to local stress concentration at the weld toe. The nominal stress amplitude increased with increasing tool rotational speed, and the values at $2 \times 10^{6}$ cycles were estimated from the S-N curves to be about 164, 214, 223, and 248 MPa in samples FSP400, FSP600, FSP800, and FSP1000, respectively. The nominal stress amplitude at $2 \times 10^{6}$ cycles in FSP1000 increased by $58 \%$ in comparison to that in the as-welded joint.

To understand the difference in nominal stress amplitude between these joints, stress concentration effects related to the weld toe geometry were investigated. The elastic stress concentration factor of $k_{t}$ and fatigue notch factor of $k_{f}$ for the butt-welded joints under the bending load were calculated from Equations (1) and (2), below, respectively [32]:

$k_{t}=1+0.165(\tan \theta)^{1 / 6}(t / r)^{1 / 2}$

$k_{f}=1+\left(k_{t}-1\right) /(1+a / r)$

where $t$ is the plate thickness of $10 \mathrm{~mm}$, and $\theta$ and $r$ are the weld toe angle and radius, respectively, measured in Figs. 2(b) and 3(a)-3(d). Peterson's material parameter of a for steels is obtained from Equation (3) [32]: 
$a=1.087 \times 10^{5} \sigma_{\text {uts }}-2$

where $\sigma_{\text {uts }}$ is ultimate tensile strength of the weld toe, obtained using the small tensile specimens. The values of $k_{t}$ and $k_{f}$ calculated in all the joints with and without FSP are summarized in Table 4, together with $t, \theta$, $r$, and $\sigma_{\text {uts }}$. The $\mathrm{k}_{\mathrm{f}}$ values of all butt-welded joints with FSP were similar and reduced by about $10 \%$ due to the significant increase in the weld toe radius, compared to that of the as-welded joint.

Table 4 Weld toe parameters for the as-welded joint, FSP400, FSP600, FSP800, and FSP1000

\begin{tabular}{|c|c|c|c|c|c|c|}
\hline Code & $\begin{array}{l}\text { Plate } \\
\text { thickness, } \\
\text { t (mm) }\end{array}$ & $\begin{array}{l}\text { Weld } \\
\text { toe } \\
\text { angle, } \\
\theta\left(^{\circ}\right)\end{array}$ & $\begin{array}{l}\text { Weld } \\
\text { toe } \\
\text { radius, } \\
\text { r(mm) }\end{array}$ & $\begin{array}{l}\text { Ultimate tensile } \\
\text { strength of the weld } \\
\text { toe, } \\
\sigma_{\text {uts }}(\mathrm{MPa})\end{array}$ & $\begin{array}{l}\text { Elastic stress } \\
\text { concentration } \\
\text { factor, } k_{t}\end{array}$ & $\begin{array}{l}\text { Fatigue } \\
\text { notch } \\
\text { factor, } k_{f}\end{array}$ \\
\hline $\begin{array}{l}\text { As- } \\
\text { welded }\end{array}$ & 10 & 27 & 0.27 & 555 & 1.90 & 1.39 \\
\hline FSP400 & & 40 & 3.69 & 637 & 1.26 & 1.25 \\
\hline FSP600 & & 32 & 2.65 & 655 & 1.30 & 1.27 \\
\hline FSP800 & & 36 & 3.53 & 672 & 1.26 & 1.25 \\
\hline FSP1000 & & 33 & 3.60 & 707 & 1.26 & 1.24 \\
\hline
\end{tabular}

The local stress amplitude [33] as fatigue strength at the weld toe of $\sigma_{\mathrm{w} \text {, loc }}$ was calculated from Equation (4):

$\sigma_{\mathrm{w}, \text { loc }}=\sigma_{\mathrm{w}, \mathrm{nom}} \cdot \mathrm{k}_{\mathrm{f}}$

where the nominal stress amplitude of $\sigma_{\mathrm{w}, \text { nom }}$ was defined as that at $2 \times 10^{6}$ cycles in Fig. 6 . Note that the $\sigma_{\mathrm{w}, \text { loc }}$ is associated with effects of factors other than the weld toe geometry modification, such as microstructure and surface roughness modification. Fig. 7 shows relationship between the calculated $\sigma_{w, l o c}$ as well as $\sigma_{\mathrm{w}, \mathrm{nom}}$ for all the joints with FSP variation with tool rotational speed, together with the $\sigma_{\mathrm{w}, \text { nom }}$ and $\sigma_{\mathrm{w}, \text { loc }}$ of the as-welded joint and the $\sigma_{\mathrm{w}, n o m}$ of the base metal. The $\sigma_{\mathrm{w}, \mathrm{loc}}$ in sample FSP400 was lower than that in the as-welded joint, even though the weld toe microstructure was significantly refined. This can be associated with the notched surface because of low heat input (Fig. 3(e)). On the other hand, values of the $\sigma_{w, l o c}$ in FSP600, FSP800, and FSP1000 with the smooth weld toe surface were obviously higher than that of the as-welded joint. Especially, the value of the $\sigma_{\mathrm{w}, \mathrm{loc}}$ in FSP1000 was about $41 \%$ higher than that of the as-welded joint. This indicates that microstructure modification in the topmost layer of weld toes provided much larger increase in fatigue strength than the weld toe geometry modification. Increase of $\sigma_{\mathrm{w}, \mathrm{loc}}$ in FSP600 can be explained by grain refinement. Those in FSP800 and FSP1000 were a little higher and much higher, respectively, than that in FSP600. The further increase in FSP800 and FSP1000 is associated with the alloying of the topmost layer of weld toes with the tool constituent elements. The alloying led to $\mathrm{W}$ and $\mathrm{C}$ solid solution hardening together with the related martensitic transformation. 
To clarify the effect of the alloyed topmost layer on the fatigue strength increase observed in samples FSP800 and FSP1000, fracture surface observation and analysis were performed. Fig. 8 shows SEM images of fracture surfaces obtained after fatigue failure at stress amplitude of $300 \mathrm{MPa}$ for all the joints with and without FSP. The observed fracture surfaces can be divided into two regions, consisting of flat surface caused by fatigue crack initiation and propagation, and rough surface corresponding to the fast fracture region. Many ratchet marks (white arrows), forming a boundary between two adjacent failure planes, were observed on the fracture surfaces beneath the weld toe surface. The more crack initiation sites there were, the more ratchet marks were present. The average number of ratchet marks per unit length on the fracture surfaces for all the joints is shown in Fig. 9. The average value in FSP400 was more than that in the as-welded joint. The enlarged crack initiation region beneath the weld toe surface showed rough, discontinuous, brittle fracture planes (Fig. $8(c)$ ). The crack initiation occurred at the notch bottom in the rough surface after FSP (Fig. 3(e)), resulting in the lower in FSP400 than that in the as-welded joint. On the other hand, the fatigue fracture surface in FSP600, FSP800, and FSP1000 was smoother and had much fewer ratchet marks than in the as-welded joint and FSP400. The average number of ratchet marks per unit length on the fracture surfaces in FSP600, FSP800, and FSP1000 decreased with increasing tool rotational speed. This suggests that resistance to crack initiation at the weld toe surface during fatigue tests can be enhanced by increasing hardness due to solid solution hardening, by alloying the topmost layer with $\mathrm{W}$ and $\mathrm{C}$ elements.

To understand the effect of the alloyed topmost layer on increase in the fatigue strength, the fatigue failure position and distributions of the alloyed tool constituent elements near the failure position were investigated. Fig. 10 shows cross-sectional OM and EPMA-W map images obtained near the fatigue failure at the stress amplitude of $300 \mathrm{MPa}$ in sample FSP1000. The EPMA-W map image indicates that the fatigue failure occurred at the surface position with lower alloyed tool constituent elements. The fatigue failure occurred at a similar position in FSP800. This suggests that alloying the weld toe surface with tool constituent elements increased resistance to fatigue crack initiation, and the crack initiated at the excess weld metal with higher thickness than that in the base metal. Especially, the increment of the alloyed $\mathrm{W}$ and $\mathrm{C}$ contents near the weld toe surface in FSP1000 was the highest, resulting in the highest hardness, leading to the largest increase in fatigue strength among all the joints with FSP modified weld toes. The increment of the alloyed W and C contents is associated with WC tool wear during FSP, and increment of both the W and C contents and WC tool wear increased with increasing tool rotational speed [31]. The tool wear has been considered as an unavoidable issue in high strength materials during FSP, but these results indicate that alloying the weld toe with tool constituent elements could be an effective technique for increasing fatigue strength of welded steel joints.

\section{Conclusions}

To clarify influence of the tool rotational speed on increasing fatigue strength, FSP was conducted on the weld toes of HSLA steel joints with various rotational speeds of 400,600, 800, and $1000 \mathrm{rpm}$. Alloying of the topmost steel layer with WC tool constituent elements of W and C occurred at high rotational speeds together with occurrence of WC tool wear at the SZ surface. Solid solution hardening increased hardness at the topmost steel layer, and the hardness increased with increasing tool rotational speed. This led to increase in 
fatigue strength and resulted in the maximum increase obtained in sample FSP1000. The important findings are as follows:

1. The average hardness of the topmost steel layer was 552 and 878 HV in samples FSP800 and FSP1000, respectively. These values were higher than hardness of the water-quenched base metal. The higher hardness was caused by solid solution hardening due to the supersaturated W and $\mathrm{C}$ in the topmost layer, which contained martensite laths. In contrast, hardness increases in the topmost layer of FSP400 and FSP600 were caused by grain refinement only.

2. The nominal stress amplitude increased with increasing tool rotational speed, and the values at $2 \times 10^{6}$ cycles (fatigue limit) were estimated to be about 164, 214, 223, and $248 \mathrm{MPa}$ in samples FSP400, FSP600, FSP800, and FSP1000, respectively. The maximum value in FSP1000 was 58\% higher than that in the as-welded joint.

3. The in sample FSP400 was lower, while those in FSP600, FSP800, and FSP1000 were obviously higher than that in the as-welded joint. The lower in FSP400 could be associated with the notched surface. Increase of in FSP600 can be explained by grain refinement. Those in FSP800 and FSP1000 were a little higher and much higher, respectively, than that in FSP600. This could be associated with the alloying of the topmost layer of the weld toes with the tool constituent elements. The alloying led to $\mathrm{W}$ and $\mathrm{C}$ solid solution hardening together with the related martensitic transformation.

4. The number of ratchet marks on the fatigue fracture surface was reduced by increasing tool rotational speed, indicating reduction of crack initiation sites. The crack tended to initiate at a weld toe surface that corresponded to the end of or a little apart from the alloyed area containing the tool constituent elements. This suggests that the $\mathrm{W}$ and $\mathrm{C}$ solid solution hardening prevented fatigue crack initiation.

\section{Declarations}

\section{Author contribution}

Hajime Yamamoto: Conceptualization, Methodology, Validation, Investigation, Data Curation, Writing - Original Draft, and Visualization. Shodai Koga: Investigation, Data Curation, and Visualization. Kazuhiro Ito: Conceptualization, Writing - Review \& Editing, and Supervision. Yoshiki Mikami: Methodology.

\section{Funding}

This work was supported by a future pioneering project commissioned by JSPS KAKENHI Grant Number JP19K23575 and the New Energy and Industrial Technology Development Organization (NEDO).

\section{Data availability}

The data presented in this study are available from the corresponding author upon reasonable request.

Ethics approval and consent to participate: Not applicable.

Consent for publication: Authors consent to publish this article. 
Competing interests: The authors declare no competing interests.

\section{References}

1. Fueki R, Takahashi K, Handa M (2019) Fatigue limit improvement and rendering defects harmless by needle peening for high tensile steel welded joint. Met 9:143. https://doi.org/10.3390/met9020143

2. Lago J, Trško L, Jambor M, Nový F, Bokůvka O, Mičian M, Pastorek F (2019) Fatigue life improvement of the high strength steel welded joints by ultrasonic impact peening. Met 9:619. https://doi.org/10.3390/met9060619

3. Hensel J, Eslami H, Nitschke-Pagel T, Dilger K (2019) Fatigue strength enhancement of butt welds by means of shot peening and clean blasting. Met 9:744. https://doi.org/10.3390/met9070744

4. Fueki R, Takahashi K (2021) Improving the fatigue limit and rendering a defect harmless by laser peening for a high strength steel welded joint. Opt Laser Technol 134:106605. https://doi.org/10.1016/j.optlastec.2020.106605

5. Kang HT, Lee Y-L, Sun XJ (2008) Effects of residual stress and heat treatment on fatigue strength of weldments. Mater Sci Eng A 497:37-43. https://doi.org/10.1016/j.msea.2008.06.011

6. Aung MP, Katsuda H, Hirohata M (2019) Fatigue-performance improvement of patch-plate welding via PWHT with induction heating. J Constr Steel Res 160:280-288. https://doi.org/10.1016/j.jcsr.2019.05.047

7. Baptista R, Infante V, Branco CM (2008) Study of the fatigue behavior in welded joints of stainless steels treated by weld toe grinding and subjected to salt water corrosion. Int J Fatigue 30:453-462. https://doi.org/10.1016/j.ijfatigue.2007.04.011

8. Fu Z, Ji B, Kong X, Chen X (2017) Grinding treatment effect on rib-to-roof weld fatigue performance of steel bridge decks. J Const Steel Res 129:163-170. https://doi.org/10.1016/j.jcsr.2016.09.018

9. Kim I-T, Kim H-S, Dao DK, Ahn J-H, Jeong Y-S (2018) Fatigue resistance improvement of welded joints by bristle roll-brush grinding. Int J Steel Struct 18:1631-1638. https://doi.org/10.1007/s13296-018-0059-1

10. Dahle T (1998) Design fatigue strength of TIG-dressed welded joints in high-strength steels subjected to spectrum loading. Int J Fatigue 20:677-681. https://doi.org/10.1016/S0142-1123(98)00031-0

11. Ramalho AL, Ferreira JAM, Branco CAGM (2011) Fatigue behaviour of T welded joints rehabilitated by tungsten inert gas and plasma dressing. Mater Des 32:4705-4713.

https://doi.org/10.1016/j.matdes.2011.06.051

12. Skriko T, Ghafouri M, Björk T (2017) Fatigue strength of TIG-dressed ultra-high-strength steel fillet weld joints at high stress ratio. Int J Fatigue 94:110-120. https://doi.org/10.1016/j.ijfatigue.2016.09.018

13. Yıldırım HC (2017) Recent results on fatigue strength improvement of high-strength steel welded joints. Int J Fatigue 101:408-420. https://doi.org/10.1016/j.ijfatigue.2016.10.026

14. Ito K, Okuda T, Ueji R, Fujii H, Shiga C (2014) Increase of bending fatigue resistance for tungsten inert gas welded SS400 steel plates using friction stir processing. Mater Des 61:275-280. https://doi.org/10.1016/j.matdes.2014.04.076

15. Yamamoto $\mathrm{H}$, Ito $\mathrm{K}$ (2018) Effects of microstructural modification using friction stir processing on fatigue strength of butt-welded joints for high-strength steels. Mater Sci Appl 9:625-636.

https://doi.org/10.4236/msa.2018.97045

Page $11 / 21$ 
16. Yamamoto H, Danno Y, Ito K, Mikami Y, Kohama K, Fujii H (2018) Application of friction stir processing to weld toe for fatigue strength improvement of high-strength low-alloy steel joint. Weld Lett 36:1WL-4WL. https://doi.org/10.2207/qjjws.36.1WL

17. Yamamoto H, Danno Y, Ito K, Mikami Y, Fujii H (2018) Weld toe modification using spherical-tip WC tool FSP in fatigue strength improvement of high-strength low-alloy steel joints. Mater Des 160:1019-1028. https://doi.org/10.1016/j.matdes.2018.10.036

18. Yamamoto H, Nishiura T, Nishibata H, Yonemura M, Fujiwara K, Kawano K, Ito K (2020) Surface microstructure modifications of low carbon steel welds produced by low-heat-input friction stir processing. Mater Trans 61:1613-1619. https://doi.org/10.2320/matertrans.MT-M2020117

19. Mishra RS, Ma ZY (2005) Friction stir welding and processing. Mater Sci Eng R 50:1-78. https://doi.org/10.1016/j.mser.2005.07.001

20. Yadav D, Bauri R (2012) Effect of friction stir processing on microstructure and mechanical properties of aluminium. Mater Sci Eng A 539:85-92. https://doi.org/10.1016/j.msea.2012.01.055

21. Sekban DM, Aktarer SM, Xue P, Ma ZY, Purcek G (2016) Impact toughness of friction stir processed low carbon steel used in shipbuilding. Mater Sci Eng A 672:40-48.

https://doi.org/10.1016/j.msea.2016.06.063

22. Xue P, Wang BB, Chen FF, Wang WG, Xiao BL, Ma ZY (2016) Microstructure and mechanical properties of friction stir processed Cu with an ideal ultrafine-grained structure. Mater Charact 121:187-194. https://doi.org/10.1016/j.matchar.2016.10.009

23. Luo XC, Kang LM, Liu HL, Li ZJ, Liu YF, Zhang DT, Chen DL (2020) Enhancing mechanical properties of AZ61 magnesium alloy via friction stir processing: Effect of processing parameters. Mater Sci Eng A 797:139945. https://doi.org/10.1016/j.msea.2020.139945

24. Ni DR, Wang D, Feng AH, Yao G, Ma ZY (2009) Enhancing the high-cycle fatigue strength of Mg-9Al-1Zn casting by friction stir processing. Scr Mater 61:568-571. https://doi.org/10.1016/j.scriptamat.2009.05.023

25. Jana S, Mishra RS, Baumann JB, Grant G (2010) Effect of friction stir processing on fatigue behavior of an investment cast Al-7Si-0.6 Mg alloy. Acta Mater 58:989-1003.

https://doi.org/10.1016/j.actamat.2009.10.015

26. Kapoor R, Kandasamy K, Mishra RS, Baumann JA, Grant G (2013) Effect of friction stir processing on the tensile and fatigue behavior of a cast A206 alloy. Mater Sci Eng A 561:159-166.

https://doi.org/10.1016/j.msea.2012.10.090

27. Silva J da, Costa JM, Loureiro A, Ferreira JM (2013) Fatigue behaviour of AA6082-T6 MIG welded butt joints improved by friction stir processing. Mater Des 51:315-322.

https://doi.org/10.1016/j.matdes.2013.04.026

28. Borrego LP, Costa JD, Jesus JS, Loureiro AR, Ferreira JM (2014) Fatigue life improvement by friction stir processing of 5083 aluminium alloy MIG butt welds. Theor Appl Fract Mech 70:68-74. https://doi.org/10.1016/j.tafmec.2014.02.002

29. Costa JDM, Jesus JS, Loureiro A, Ferreira JAM, Borrego LP (2014) Fatigue life improvement of mig welded aluminium T-joints by friction stir processing. Int J Fatigue 61:244-254.

https://doi.org/10.1016/j.ijfatigue.2013.11.004

Page $12 / 21$ 
30. Jesus JS, Costa JM, Loureiro A, Ferreira JM (2017) Fatigue strength improvement of GMAW T-welds in AA5083 by friction-stir processing. Int J Fatigue 61:124-134.

https://doi.org/10.1016/j.ijfatigue.2016.12.034

31. Yamamoto H, Imagawa Y, Ito K, Chen K, Zhang L (2021) Alloying a topmost steel-plate layer with WC-tool constituent elements during friction stir processing. J Manuf Process 69:311-319.

https://doi.org/10.1016/j.jmapro.2021.07.050

32. Yung J-Y, Lawren FV (1985) Analytical and graphical aids for the fatigue design of weldments. Fatigue Fract Eng Mater Struct 8:223-241. https://doi.org/10.1111/j.1460-2695.1985.tb00424.x

33. Hearn EJ (1997) Chapter 10 - Contact stress, residual stress and stress concentrations. In: Mechanics of materials 2 (3rd edn.) An introduction to the mechanics of elastic and plastic deformation of solids and structural materials, pp. 381-442. https://doi.org/10.1016/B978-075063266-9/50011-1

\section{Figures}

(a)
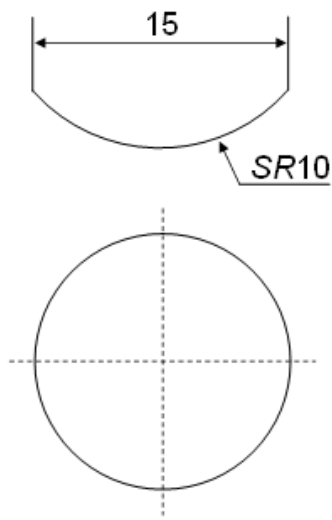

(b)
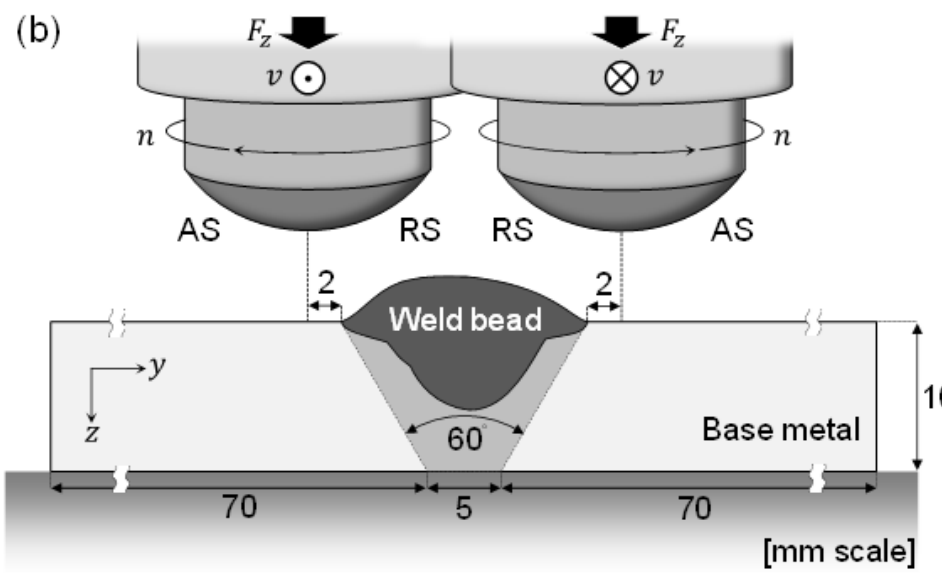
$\otimes v$ (c)

10

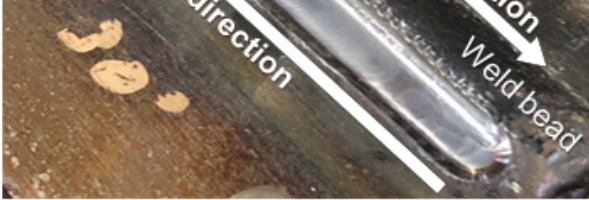

\section{Figure 1}

Schematic illustrations of (a) a tool shape and (b) arrangement of the tool and a weld toe during FSP. (c) A photo image of a typical FSP operation with the tool rotational speed of $1000 \mathrm{rpm}$ 
(a) As-welded

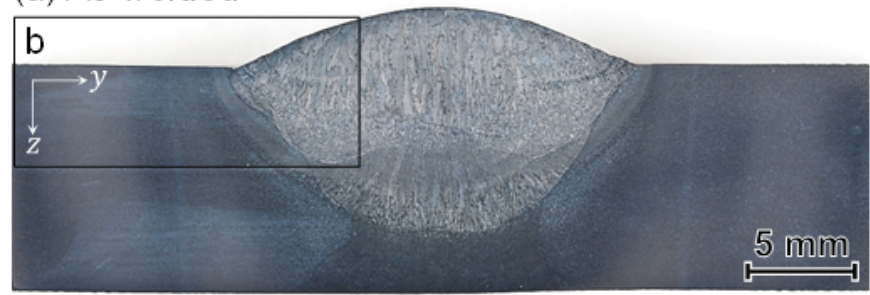

(b)

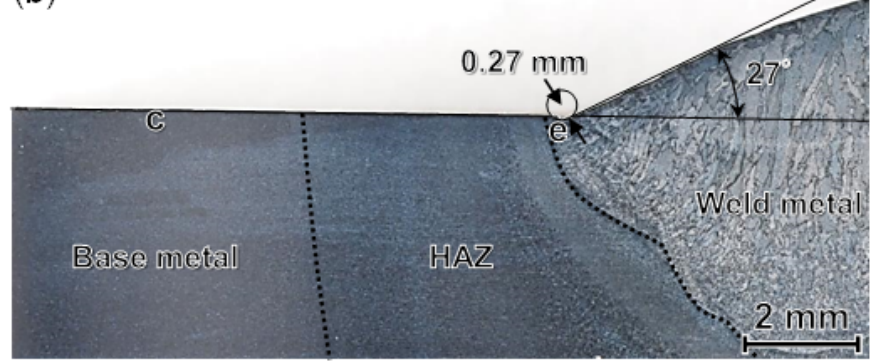

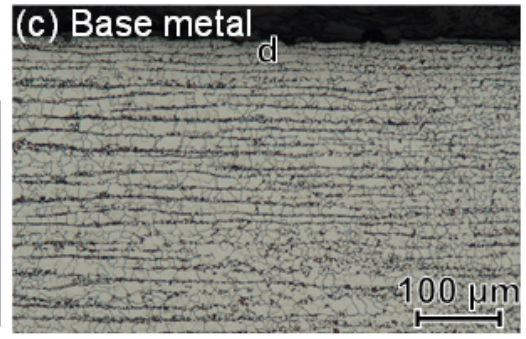
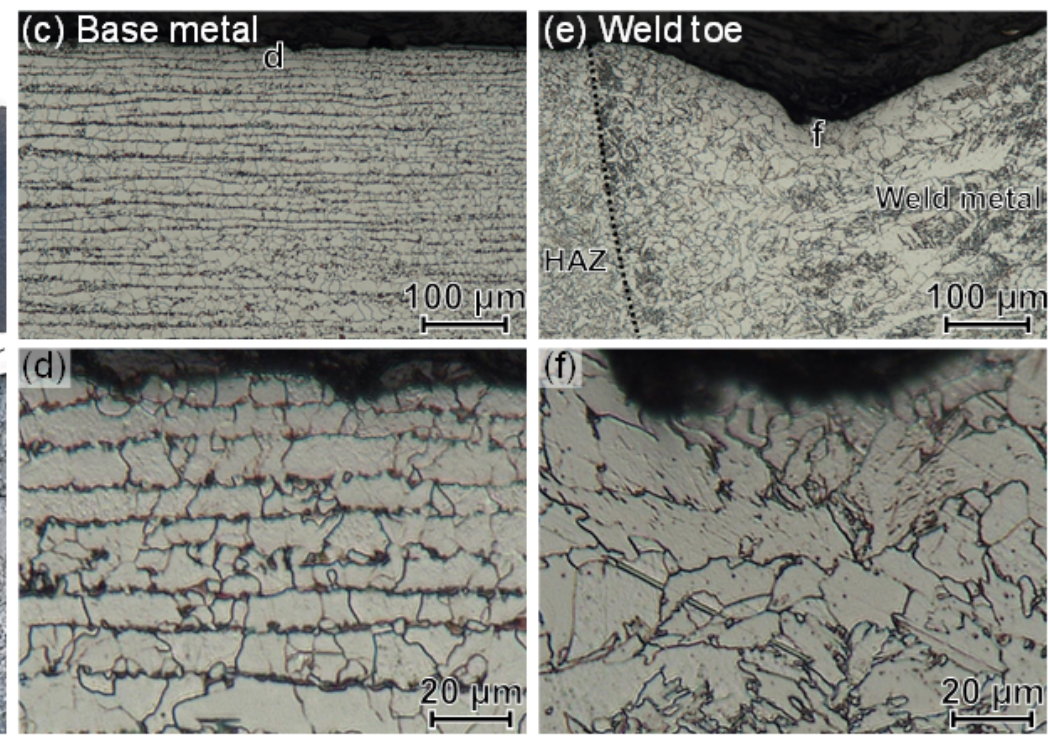

\section{Figure 2}

(a) Cross-sectional OM image of the whole weld in an as-welded joint and (b) enlargement of rectangular frame in a. (c), (d) Cross-sectional OM images of typical base metal portions and (e), (f) typical weld toe portions in a

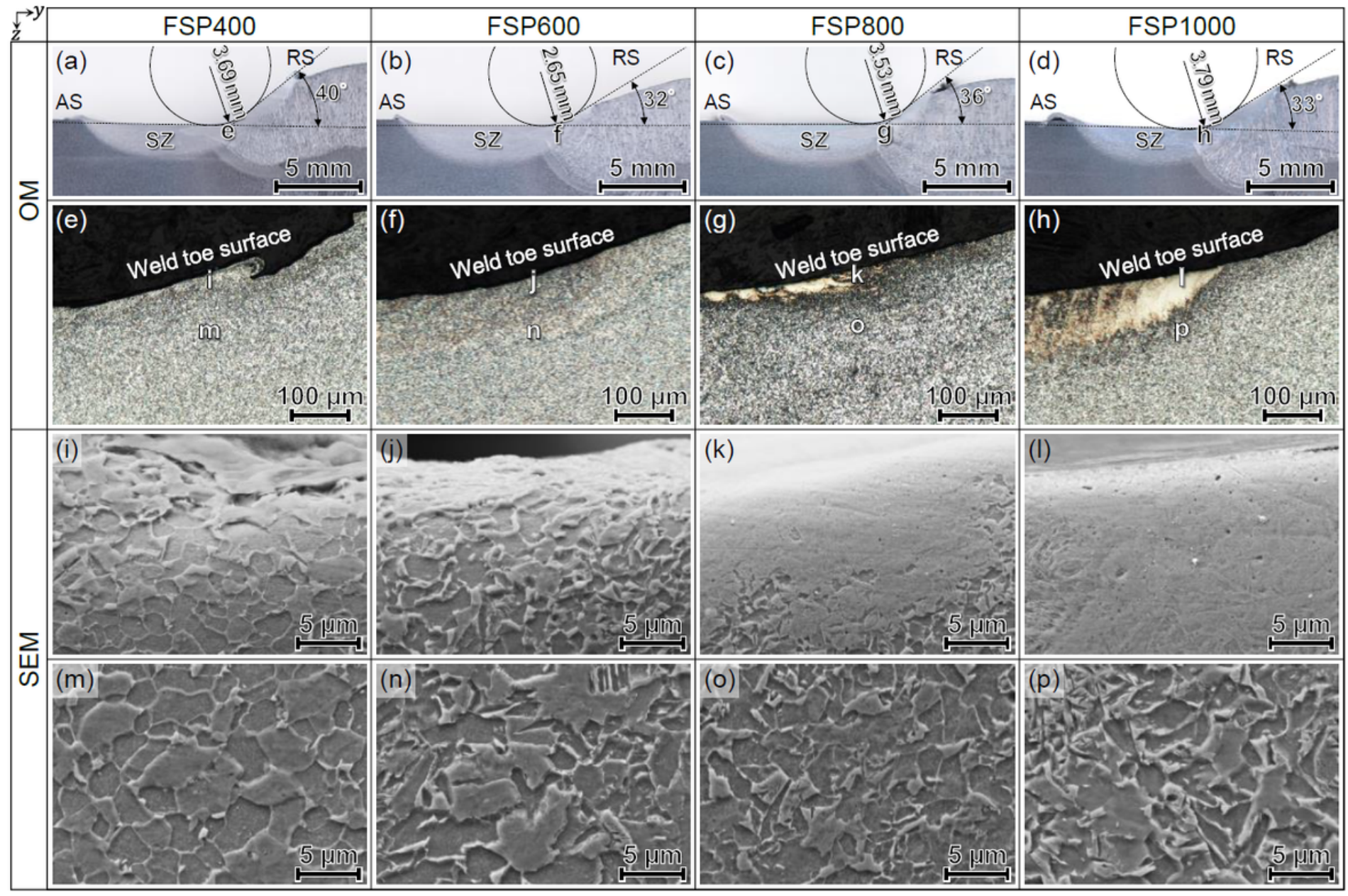

Figure 3 
Cross-sectional OM images of weld toes in samples (a), (e) FSP400, (b), (f) FSP600, (c), (g) FSP800, and (d), (h) FSP1000; and (i)-(p) SEM enlargements of positions $i$ and $m$ in (e), $j$ and $n$ in (f), $k$ and $o$ in $(g), I$ and $p$ in (h)

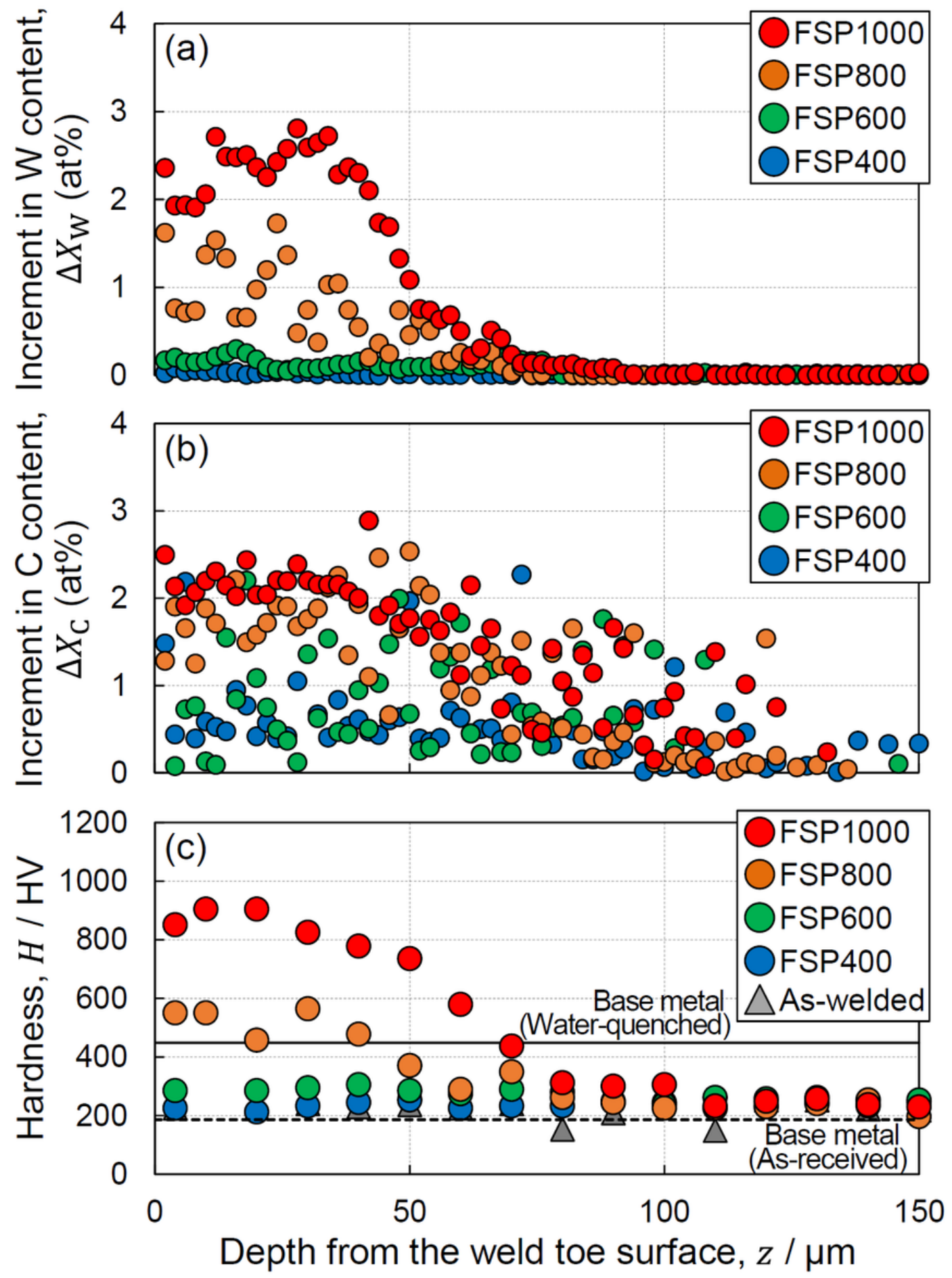

Figure 4

Variation of increment in (a) W and (b) C contents, (c) hardness with depth from the surface in the topmost layer of weld toes for as-welded joints with and without FSP, depending on tool rotational speed 


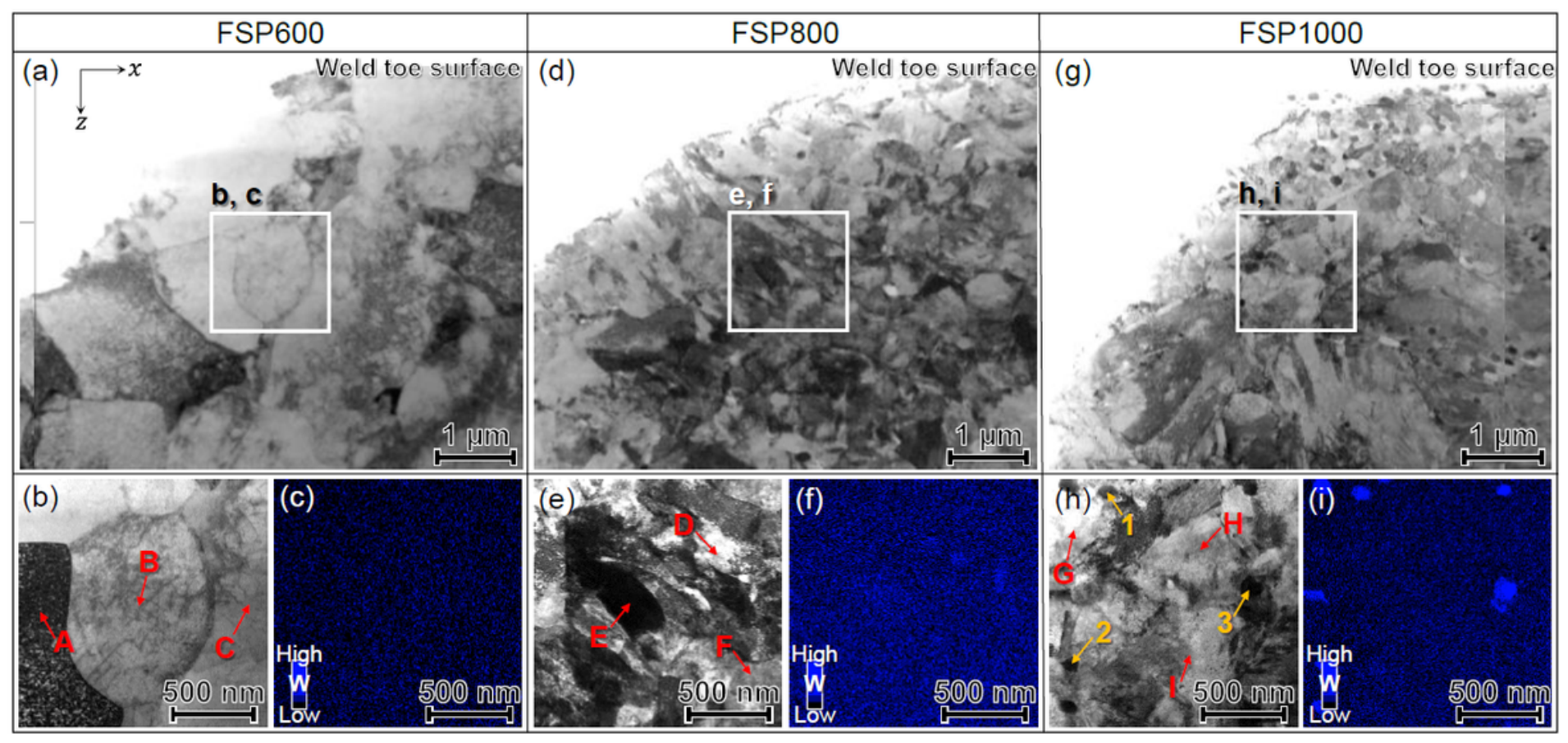

Figure 5

TEM-BF and EDS-W map images obtained from the outermost surface layer in weld toes for samples (a)-(c) FSP600, (d)-(f) FSP800, and (g)-(i) FSP1000 


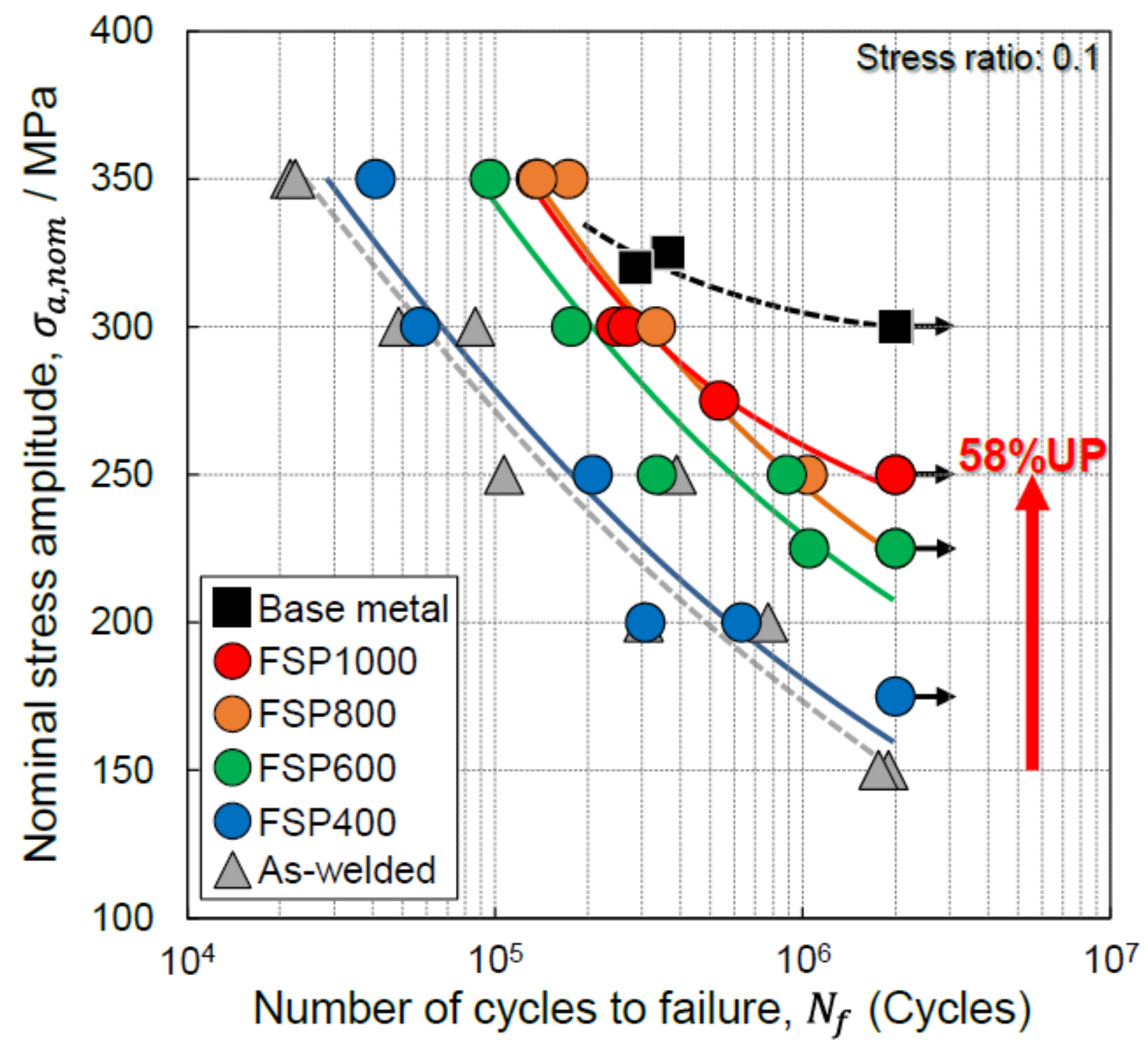

Figure 6

S-N diagram obtained in four-point bending fatigue tests for samples FSP400, FSP600, FSP800, and FSP1000, together with those for an as-welded joint and a base metal 


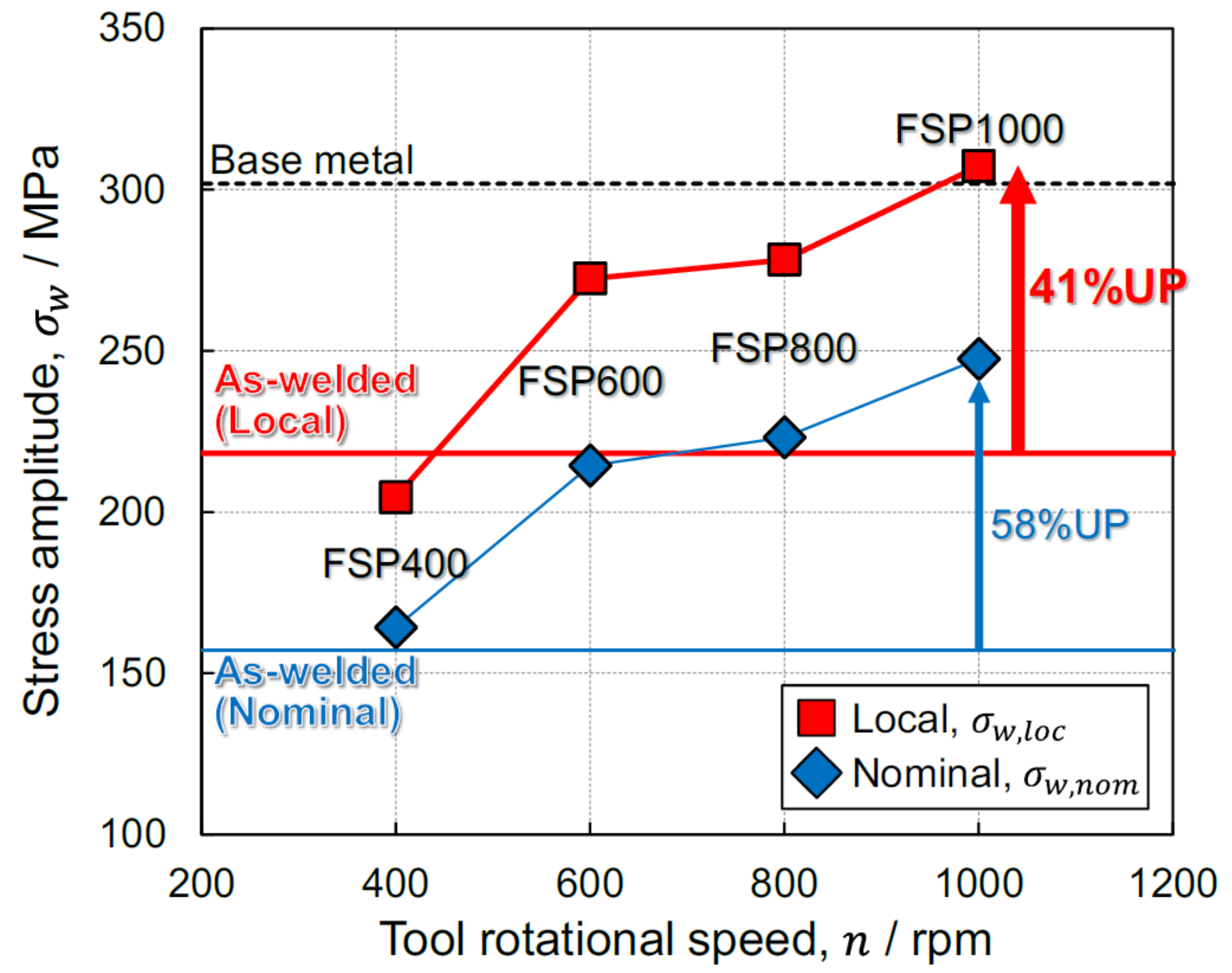

Figure 7

Nominal and local stress amplitude variation with tool rotational speed in samples FSP400, FSP600, FSP800, and FSP1000 
(a) As-welded

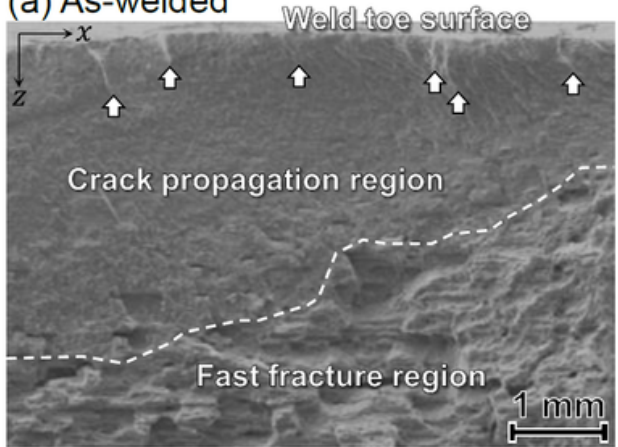

(d) FSP600

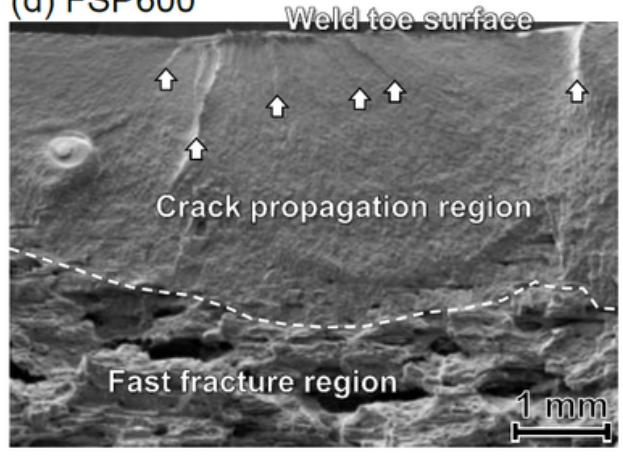

(b) FSP400

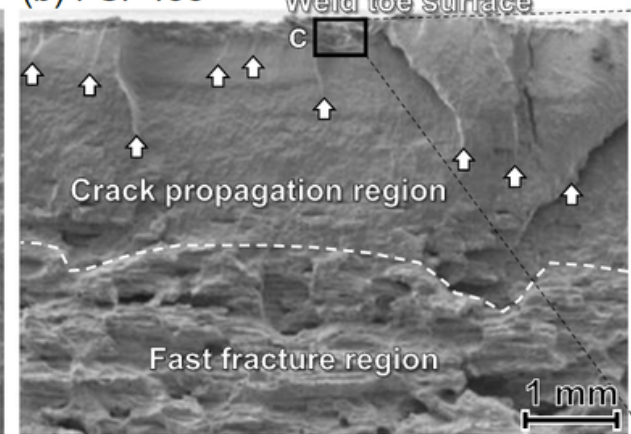

(e) FSP800

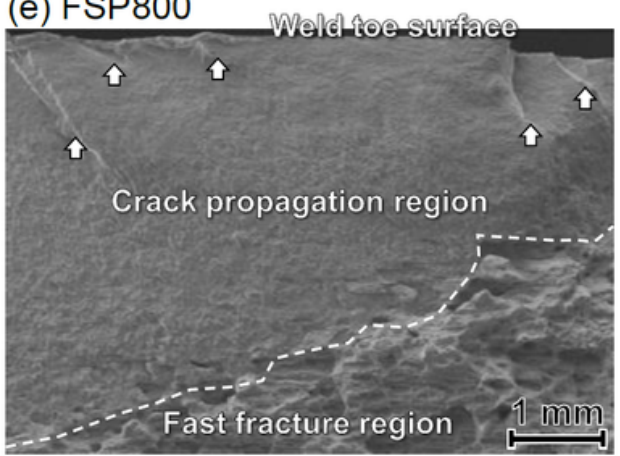

(c)

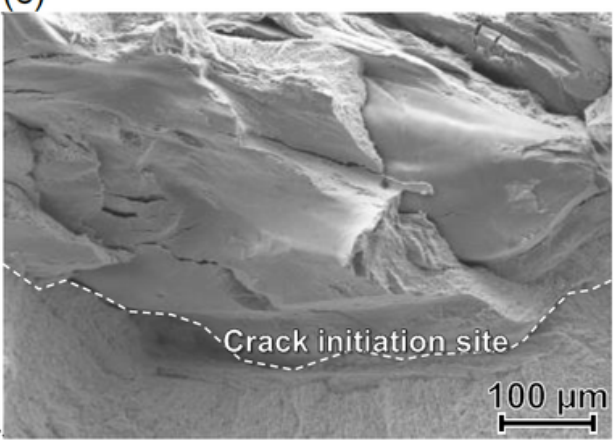

(f) FSP1000

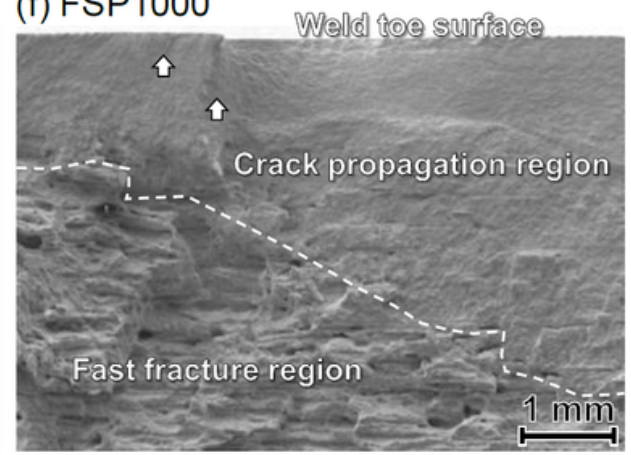

\section{Figure 8}

SEM images of the fracture surface obtained after fatigue failure at stress amplitude of $300 \mathrm{MPa}$ for the (a) as-welded joint, (b) and (c) FSP400, (d) FSP600, (e) FSP800, and (f) FSP1000 


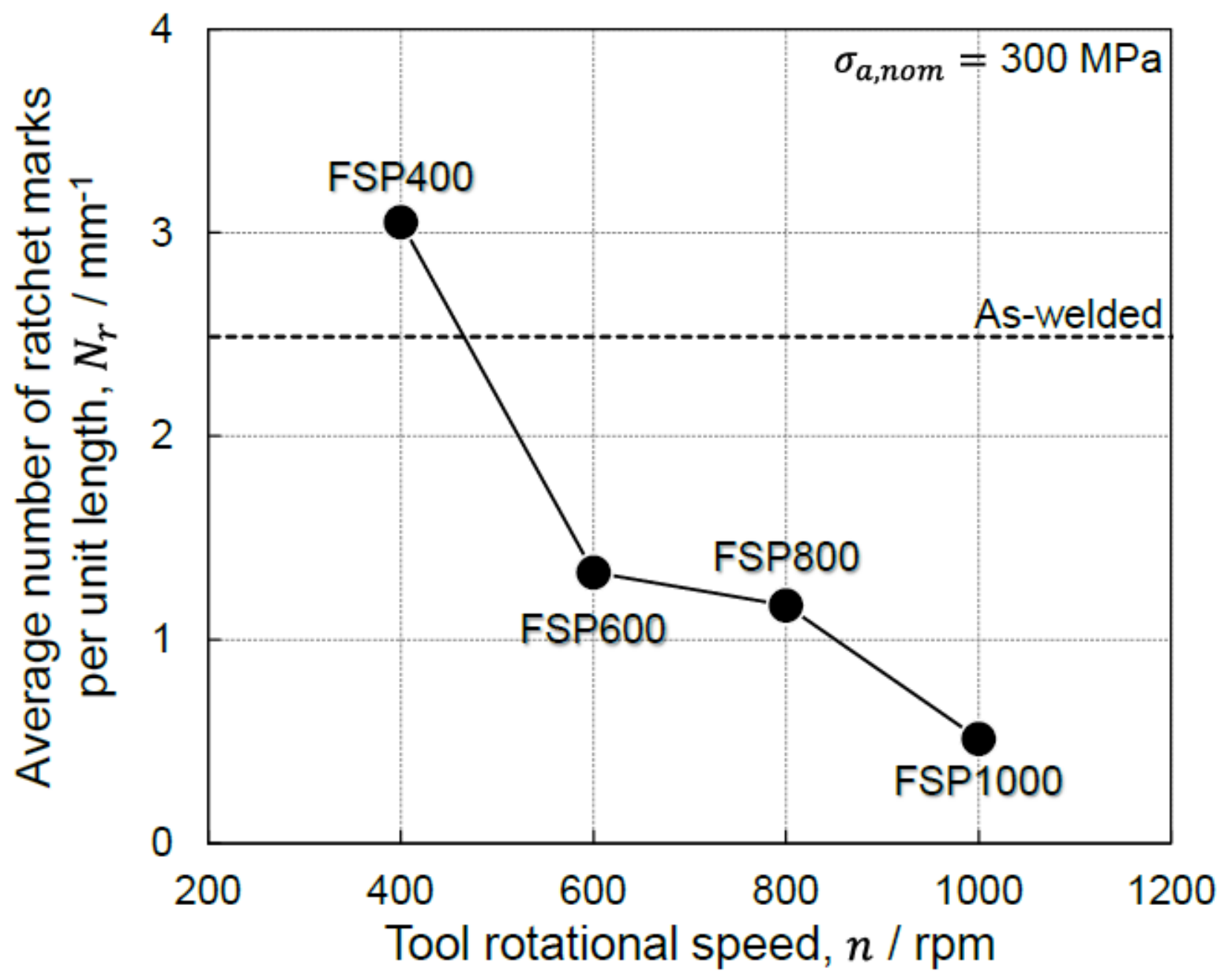

Figure 9

Average number of ratchet marks per unit length on fracture surfaces after fatigue failure at stress amplitude of $300 \mathrm{MPa}$ in the as-welded joint, FSP400, FSP600, FSP800, and FSP1000 


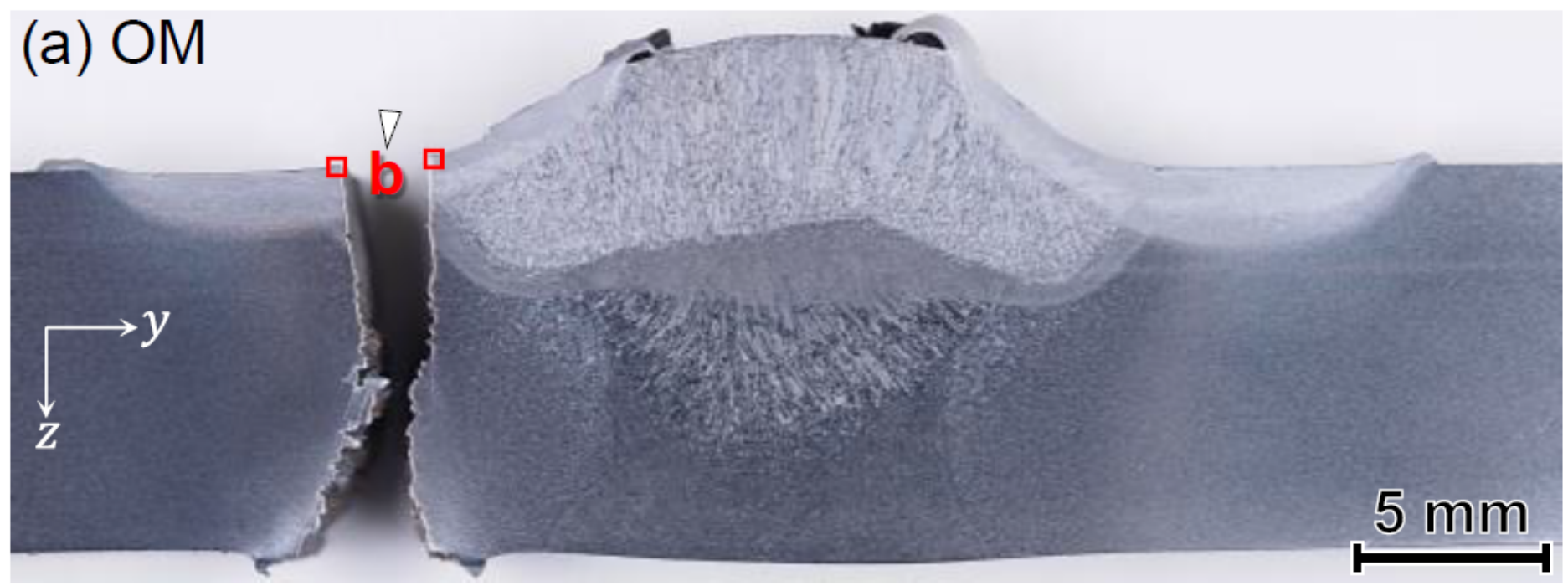

\section{(b) EPMA-W}

Alloyed layer

\section{Crack initiation site}

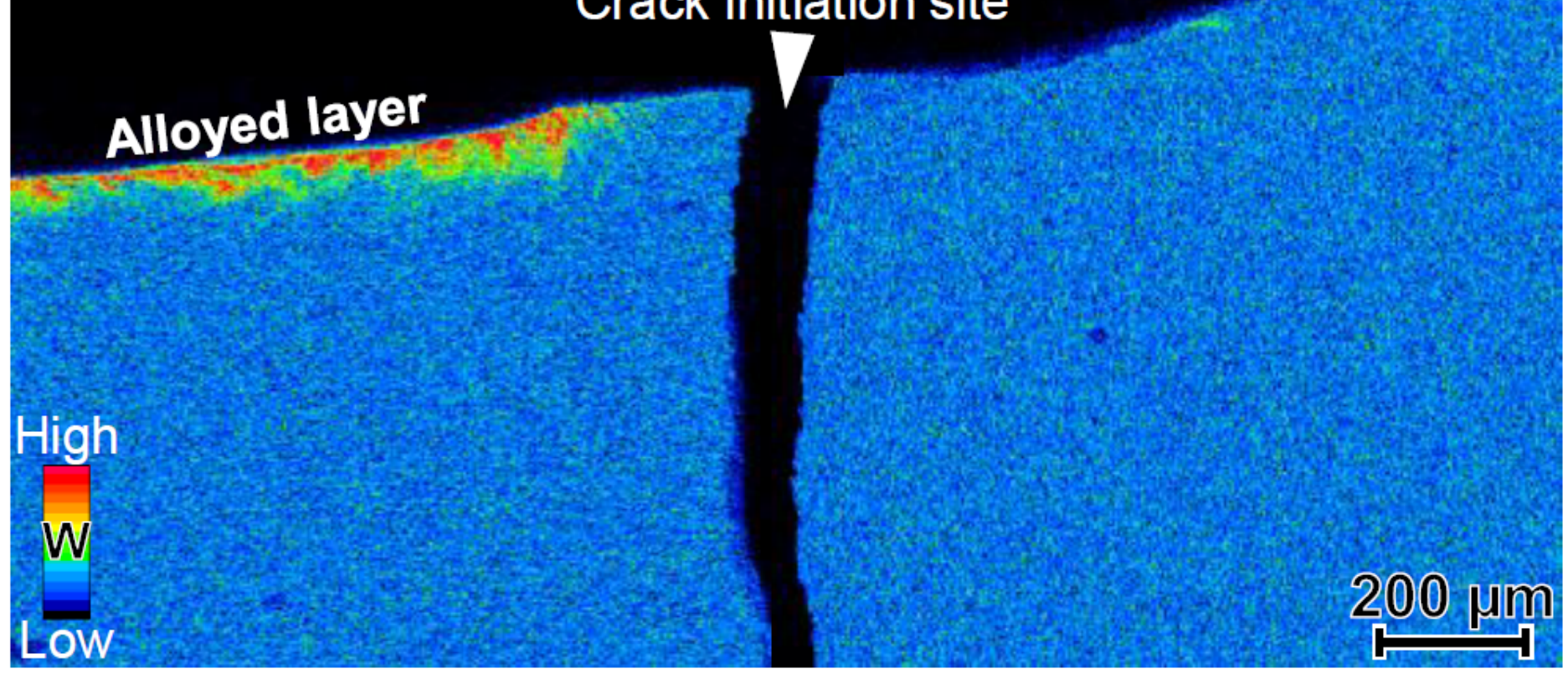

Figure 10

(a) Cross-sectional OM image of sample FSP1000 after fatigue failure at stress amplitude of $300 \mathrm{MPa}$ and (b) EPMA-W map image obtained at the enlarged area $b$ in $a$ 